\title{
Impact of Quality and Usage of Outdoor Spaces on Sustainable Campus Environment in Akure, Nigeria
}

\author{
Ikudayisi Ayodele Emmanuel*, Adegbehingbe Victor Olufemi \\ Department of Architecture, Federal University of Technology, Akure, Nigeria \\ Email address: \\ ayoikudayisi@gmail.com (A. E. Ikudayisi),victoradegbehin22@gmail.com (V. O. Adegbehingebe) \\ ${ }^{*}$ Corresponding author
}

To cite this article:

Ikudayisi Ayodele Emmanuel, Adegbehingbe Victor Olufemi. Impact of Quality and Usage of Outdoor Spaces on Sustainable Campus Environment in Akure, Nigeria. American Journal of Environmental Protection. Vol. 6, No. 5, 2017, pp. 105-111. doi: 10.11648/j.ajep.20170605.11

Received: February 28, 2017; Accepted: April 1, 2017; Published: August 29, 2017

\begin{abstract}
Sustainable academic environment has multiple benefits of fostering conducive living and learning as well as shaping student's behavioural pattern towards sustainability practice in their future endeavours. Although an academic environment entails the interface of indoor and outdoor spaces, the outdoor spaces have received little research attention especially in Nigeria. This study focused on outdoor sustainability by examining the qualities, adequacy and level of usage of campus outdoor spaces and its infrastructures. An instrument tagged "Campus Outdoor Spaces Questionnaire (COSQ)" was used to collect relevant data from Four hundred and Ten (410) students drawn from six (6) Schools in Federal University of Technology Akure, (FUTA) Nigeria. The data collected were analysed using descriptive statistics including frequency chart, mean score and standard deviation. The study found that the students perceived the campus outdoor spaces as well landscaped, well maintained and safe; however, they opined that the outdoor furniture, sport facilities and lighting are grossly inadequate, more importantly; the outdoor spaces lack facilities that could support learning and social connectivity. Hence, recommendations were made on strategies towards achieving sustainable campus environments, urging universities to implement outdoor projects that support learning, students' interaction and ultimately foster sustainable environment.
\end{abstract}

Keywords: Campus, Environment, Outdoor Spaces, Students' Perception, Sustainable Development

\section{Introduction}

Sustainable development entails taking care of man's present need for food, shelter, transportation, energy, and natural/industrial products while conserving resources and protecting quality of the environment for future generation. Hence, the concept recognizes the importance of meeting both immediate and long- term needs of man through conservation and effective management of physical and biological resources. In the past three decades, the concept of sustainable development has been widely used since the release of Brundtland report $[1 ; 2]$. Sustainability is a growing global issue that has attracted attention of individuals, governments and institutions including the educational institutions. As noted by David and Wolski [3] and Abd-Razak et al., [4], many universities around the world have shown commitment towards sustainability through sustainable campus planning, management as well as adopting different approaches to learning sustainability process.

The educational environment in a campus setting holistically entails the interface of indoor and outdoor spaces. At any level of education, the outdoor space is an essential consideration for designers or school administrators [5]. Similarly, campus environment can be classified into the physical environment and the social environment even as the duo has significant implications for planning and administration [6]. While the physical environment serves as the physical location where campus life or activities takes place, the social environment are the locations for interaction, social norms and connection among students, staff and other member of the university community [6].

Campus is a place for knowledge, a place where leaders are made, behaviour are shaped; hence has a predominant potential for promoting sustainability practice. In this regard, 
sustainable campus environment creates opportunities for higher academic institution to experiment, teach, practice and exhibit a typical model of sustainable community to larger society [7]. Dober [8] posit that higher education has the leading role of investigating and exhibiting sustainable physical planning methods that are beneficial to individual institutions and applicable to the larger community. This cannot be achieved without integrated and cognitive quality of the campus environment.

According to Lynch, the principles of physical form, such as livability, mobility, character, connection, and diversity decides the qualities of the environment [9]. Willie [10] and Smith et al., [11] argued that the physical elements of the environment contributes to the quality of a community attainable through proper techniques and procedures as well as people and elements. Hence, the physical environment of a campus should reflect harmony with nature, functionality, legibility, orderliness and show high environmental qualities. It is however very lamentable that only few campuses are organized with purposeful incorporation of sustainable values in Nigeria, despite universally recognized benefits that such plans afford. Adeyemi and Igbineweka, [12] emphasize the significance of physical infrastructures on the quality of academic programmes stressing that inadequacy of physical facilities could result into overcrowding, stress, unruly behaviour, distractions and gradual decay of symbolic things that help pattern human behaviour.

Although, most Universities in Nigeria are developing in terms of physical facilities such as construction of new lecture theaters, administrative buildings, faculty buildings, auditoriums amongst others, yet, little attention has been paid to outdoor spaces that supports social interaction, quality living, learning and ultimately enhances sustainability. Hence, this study was carried out at Federal University of Technology Akure Nigeria (FUTA) with the goal of understanding student's perception on the sustainability quality of campus outdoor environment.

Increasingly, evidence is linking quality of outdoor spaces, adequacy of its infrastructure and usage of built environment to sustainability. Several recent reviews $[10 ; 13 ; 14]$ have identified that quality of open spaces determines the overall sustainability value of a neighbourhood which also cumulates into global- scale sustainability. Following from these, the objectives of this study are to;

(1) examine the students' perception on quality of campus outdoor spaces;

(2) evaluate the adequacy of campus outdoor spaces and its infrastructures; and

(3) determine the level of usage of campus outdoor spaces.

Sustainable development suggests balancing the relationships between environmental, social, economic and health. In the context of campus environment, sustainable development means "incorporating the efficiency and complexity of nature into the landscape, restoring damaged ecologies, increasing biodiversity, promoting human health, and providing secure livelihoods while also managing expectations of the campus aesthetic" [13: p2). This suggests that a campus environment must be sustainable not only ecologically, but also socially and economically for it to complement the institution's buoyancy and health both in the present and future.

Previous study reveals the correlation between quality and adequacy of infrastructure and level of usage within campus environment. For instance, Aydin and Ter [15] study at Selcuk University, Turkey reveal that cleanliness, good landscaping, proximity to users of indoor spaces, level of satisfaction, characteristics of users, amusement potential and safety summed up to influence the level of outdoor usage. In a similar perspective, Yang and Stephen (cited in 16) at the University of Hong Kong observed that availability of outdoor furniture, attractive water theme, spatial design and proximity, weather condition, diversified plant species, work program, space sizes among others determines the use of green areas within the campus. Furthermore, Downs and David [17] suggest that architectural legibility, spatial identity, and street signage are among the main factors of cognitive mapping, perception and socio-behavioural preference in a physical environment. To date, studies on campus outdoor environment sustainability remains scanty in Nigeria. Therefore, this study examines the physical quality, adequacy of outdoor spaces and pattern of usage and its implications for campus sustainability.

\section{Material and Method}

\subsection{The Study Area}

The study area 'Federal University of Technology, Akure' (FUTA) is situated in Akure, Ondo state, Nigeria within an academic protected area of about 5 kilometers distant in radii. It is geographically geo-referenced on coordinate lines of $734393 \mathrm{E}, 808614 \mathrm{~N}$; on the western flank and 737291E, $806714 \mathrm{~N}$ on the Eastern flank of meridians. Awule Community bound the University to the south; Ipinsa settlements /Akure-Ilesa Express way to the north, Ilara and Ibule Community on the west while to the east is southern part of Akure Metropolis. At present, Federal University of Technology is composed of Seven (7) schools of study which includes; School of Agriculture and Agricultural Technology (SAAT), School of Engineering and Engineering Technology (SEET), School of Environmental Technology (SET), School of Earth and Mineral Sciences (SEMS), School of Science (SOS), School of Management Technology (SMAT) and School of Postgraduate Studies (SPGS). The University was established in 1981 and currently has 13,000 Undergraduates students and 2,000 Postgraduate students.

\subsection{Methods}

The targeted research population is the undergraduate students of Federal University of Technology; Akure estimated to about 13,000 students who study and lives within the academic environs. Following Kothari $\{18\}$, the minimum sample size was determined thus: 


$$
\text { SS }=\frac{\mathrm{Z}^{2} *(\mathrm{p}) *(1-\mathrm{p}) *(\mathrm{~N})}{\mathrm{C}^{2}(\mathrm{~N}-1)+\mathrm{Z}^{2} *(\mathrm{p}) *(1-\mathrm{p})}
$$

Where: $Z=Z$ value $(95 \%$ confidence level $), p=$ percentage 5\% (.5 used for sample size needed), $\mathrm{c}=$ confidence interval (0.05). Substituting the value of student's population of 13,000 for the equation (1) above, the sample size (ss) was determined as follows;

$$
\text { ss }=\frac{(1.96)^{2} *(0.5) *(1-0.5) *(13,000)}{(0.05)^{2}(13,000-1)+(1.96)^{2} *(0.5) *(1-0.5)}
$$

Therefore, the minimum sample size is 373 .

\subsection{Data Collection}

This study used stratified random sampling techniques. Seventy-five (75) students were randomly selected from each of the six schools totaling Four hundred and Fifty (450) students selected. Data collection was carried out between 8 September and 26 October 2016. The instrument employed were copies of well-structured questionnaires tagged "Campus Outdoor Spaces Questionnaire (COSQ)" containing closed ended questions. The primary data were collected through the help of volunteers' students of the Department of Architecture, FUTA who administered, monitored and collected all the completed questionnaires. Of the 450 questionnaires administered, only Four hundred and Ten (410) questionnaires $(91.1 \%)$ were returned and found fit for the study and thus, used for this analysis. The Four hundred and Ten (410) students responded to 23- items on the questionnaire on a Three-point-Likert type scale of; "Agreed" - 3, "Neutral" - 2, "Disagreed" - 1 and Two-point Likert type scale; "Yes"-1 and "No" - 2. Descriptive statistics including frequency distribution, mean score, and standard deviation, were used for the data analysis.

\section{Data Analysis and Discussion}

\subsection{Characteristics of Respondents}

The School distribution of the respondents are as follows:

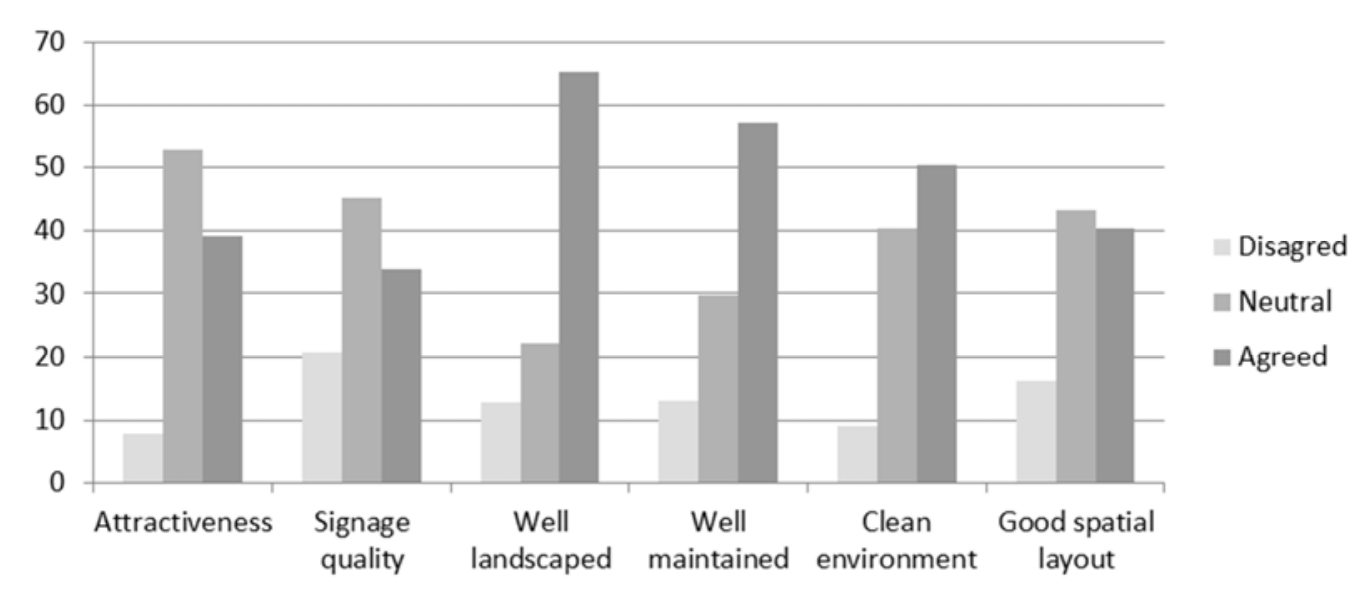

Figure 1. Frequency Distribution for Assessment of Quality.
School of Agriculture and Agricultural Technology (SAAT) $64(15.6 \%)$, School of Earth and Mineral Sciences (SEMS) $60(14.6 \%)$, School of Engineering and Engineering Technology (SEET) 74 (18.0\%), School of Environmental Technology (SET) 73 (17.8\%), School of Science (SOS) 73 $(17.8 \%)$ and School of Management Technology (SMAT) 66 (16.1\%). Likewise, the level distribution of the respondents are as follows; 100 Level-88 (21.5\%), 200 Level-94 (22.9\%), 300 Level 75-(18.3\%), 400 Level-73 (18.3\%) and 500 Level$78(19.0 \%)$. Of all the respondents, $124(30.2 \%)$ are Female while $286(69.8 \%)$ are Male in which $86(21.0 \%)$ resides oncampus with $324(79.0 \%)$ resides off-campus (See Table 1). The distribution of the respondents across the schools and academic levels in the university indicates that the result from this study can be generalized for the study population.

Table 1. Characteristics of Respondents.

\begin{tabular}{lll}
\hline Variables & Frequency & Percentages \\
\hline School of respondents & & \\
SAAT & 64 & 15.6 \\
SEME & 60 & 14.6 \\
SEET & 74 & 18.0 \\
SET & 73 & 17.8 \\
SOS & 73 & 17.8 \\
SMAT & 66 & 16.1 \\
Level distribution of respondents & & \\
100 & 88 & 21.5 \\
200 & 94 & 22.9 \\
300 & 75 & 18.3 \\
400 & 75 & 18.3 \\
500 & 78 & 19.0 \\
Gender of respondents & & \\
Male & 286 & 69.8 \\
Female & 124 & 30.2 \\
Place of resident of respondents & & \\
on-campus & 86 & 79.0 \\
off-campus & 324 & \\
\hline
\end{tabular}

\subsection{Assessment of Quality of Outdoor Spaces}

The students' evaluation of quality of outdoor spaces were rated on 3-point Likert Scale ranging between "Disagreed", "Neutral" and "Agreed". The result of the study is as shown in Figure 1. 
The results on the assessment of outdoor quality reveals that; $33(8.0 \%)$ disagreed that the environment is attractive, $216(52.7 \%)$ were neutral while $161(39.3 \%)$ agreed that FUTA campus is beautiful and attractive. Also, 85 (20.7\%) disagreed that there are enough signage within the campus, $186(45.4 \%)$ were neutral while $139(33.9 \%)$ believed that signage are adequately provided within the campus. As regards the quality of landscapes, $52(12.7 \%)$ disagreed that the campus is well landscaped, $91(22.2 \%)$ were neutral while a higher percentage of $267(65.1 \%)$ agreed that FUTA campus is well landscaped. These results are related to Adedeji and Fadamiro [16] study at LAUTECH Nigeria in which the students expressed high satisfaction with quality of trees planting and outdoor shading. A similar study of four universities campuses in Malaysia also revealed that the landscape quality within the campus is satisfactory to the students [4].

Furthermore, on maintenance of outdoor spaces, 53 $(12.9 \%)$ disagreed with level of maintenance, $122(29.8 \%)$ were neutral while most respondents 235 (57.3\%) agreed that the outdoor spaces are well maintained. The perception of students on cleanliness of the outdoor spaces differs as follows; 37 (9.0\%) disagreed with level of cleanliness, 166 (40.5\%) were neutral while 207 (50.5\%) believed that the campus is mostly clean. Regarding the spatial arrangement of building and outdoor spaces, 66 (16.1\%) disagreed with the spatial configuration of the campus, 178 (43.4\%) were neutral while $166(40.5 \%)$ opined that the spatial arrangement is good enough. (See also Figures 2-5).

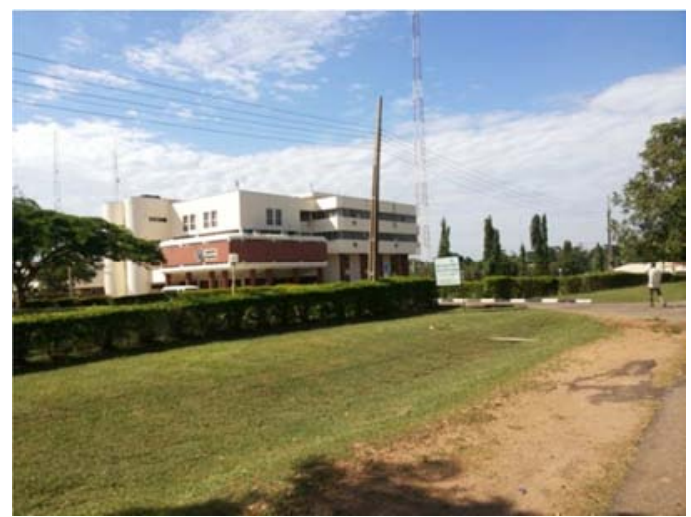

Figure 2. Landscaped area around the University Senate building (Source; Author's field survey, 2016).

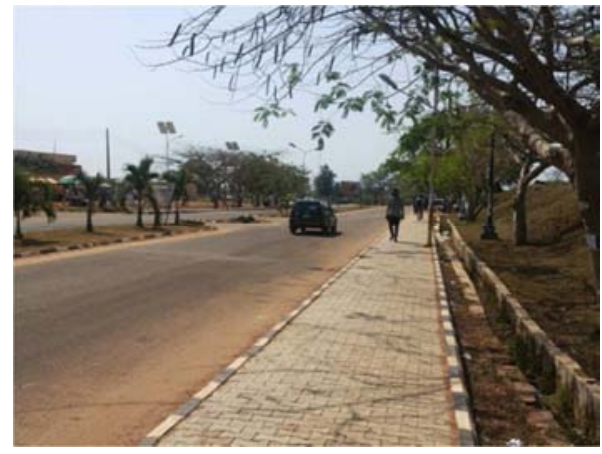

Figure 3. Walkway within FUTA campus (Source; Author's field survey, 2016).

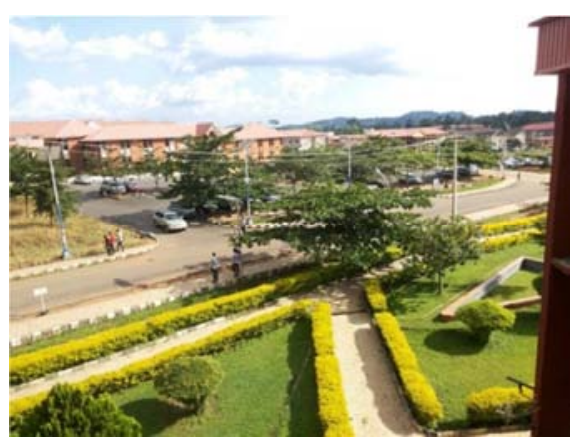

Figure 4. Landscaped area around School of Environmental Technology (SET), FUTA. (Source; Author's field survey, 2016).

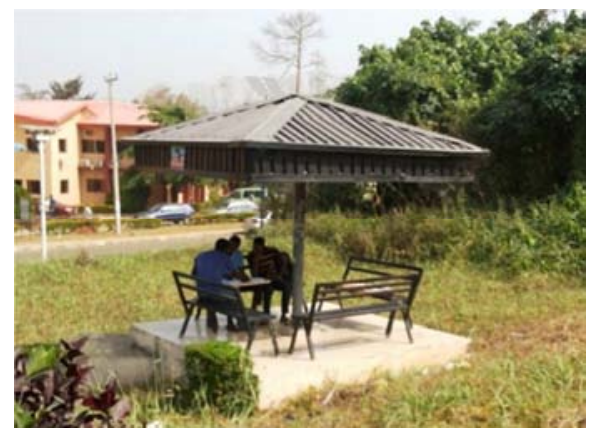

Figure 5. Covered Outdoor furniture beside School of Earth and Mineral Sciences (SEMS), FUTA (Source; Author's field survey, 2016).

\subsection{Assessment on Adequacy of Outdoor Infrastructure}

The students also assessed the adequacy of outdoor spaces facilities. Figure 6 shows the frequency distribution of the respondents.

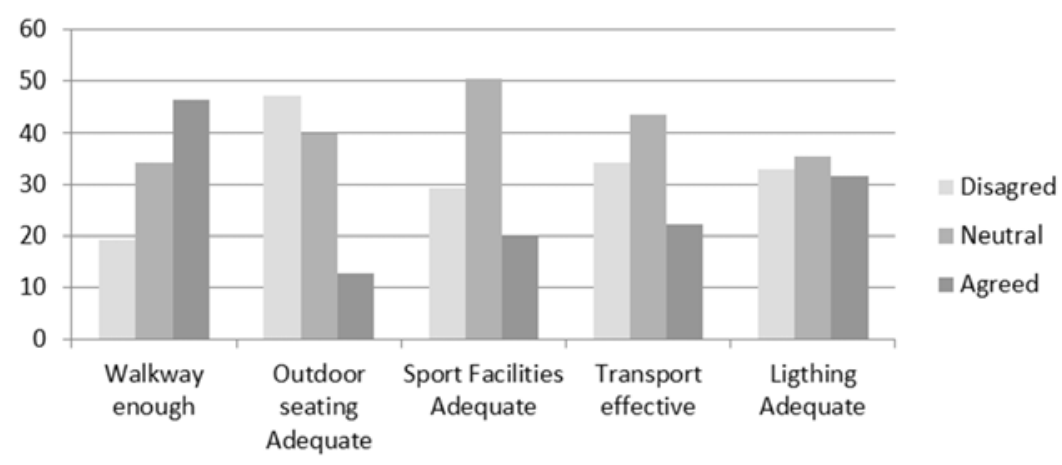

Figure 6. Frequency Distribution for Assessment of Adequacy of Outdoor Infrastructure. 
In all, $79(19.3 \%)$ opined that walkways within the campus are inadequate, 140 (34.1\%) were neutral while 191 (46.6) agreed that the pedestrian walkways are sufficient. As for the Outdoor furniture, the result reveals that a significant number of the respondents representing $194(47.3 \%)$ believed that the outdoor furniture are insufficient, $164(40.0 \%)$ were neutral while only $52(12.7 \%)$ agreed that the outdoor furniture are sufficient. The study also reveals students' evaluation on availability of sporting facilities; 120 (29.3\%) disagreed on the adequacy of the sporting facilities, 207 (50.5\%) were neutral while only $83(20.2 \%)$ believed that sporting facilities are adequate. As to transportation system within the campus, 140 $(34.1 \%)$ believed that transportation mode is inefficient, 179 (43.7\%) were indifferent while $91(22.2 \%)$ opined that transport systems are effective. The adequacy of outdoor lighting as reported by the respondents is as follows; 135 (32.9\%) opined that lighting facilities are inadequate, $146(35.6 \%)$ were neutral while 129 (31.5\%) acknowledged that the lighting are adequate. On the aspect of outdoor furniture and streetlight, this finding is similar to Adedeji and Fadamiro [16] result at LAUTECH campus in which students expressed dissatisfaction on adequacy of outdoor furniture and streetlight.

\subsection{Ranking of Outdoor Spaces Quality}

As indicated in Table 2, the Mean score ranking of outdoors shows that "Outdoor furniture" was ranked least $(\mathrm{M}=1.65)$ among the twelve variables examined whereas "Good landscape" has the highest Mean Score $(\mathrm{M}=2.52)$. For proper judgement and interpretation of findings, the decision rule for this research are as follows; score range 3-2 rated as (High Quality) and $<2-1$ as (Low Quality). Thus, the result (see Table 2) shows that the Mean Score for good landscaping, maintenance, cleanliness, attractiveness/ visual quality, adequacy of walkway and good spatial layout falls within "High Quality" scale. This suggests that the most respondents believed that campus outdoor spaces have high quality in these aspects. However, the students rating on adequacy of outdoor seating, sport facilities, transportation and lighting falls between ranges $<2-1$, thus indicating "Low Quality" perception by the respondents. It is important to note that the Standard deviation on quality rating among the variables ranges from $0.803-0.614$, which significantly indicates relative consistency in responses among the sampled population.

Table 2. Mean Score, Standard Deviation and Ranking of outdoor spaces quality.

\begin{tabular}{llll}
\hline Variables & Mean & Std. Deviation & Ranking \\
\hline Good landscape & 2.52 & .710 & $1^{\text {st }}$ \\
Well maintained environ. & 2.44 & .712 & $2^{\text {nd }}$ \\
Clean environment & 2.41 & .651 & $3^{\text {rd }}$ \\
Attractiveness/ Visual quality & 2.31 & .614 & $4^{\text {th }}$ \\
Walkway adequate & 2.27 & .765 & $5^{\text {th }}$ \\
Good Spatial arrangement & 2.24 & .712 & $6^{\text {th }}$ \\
Signage adequate & 2.13 & .728 & $7^{\text {th }}$ \\
Lighting adequate & 1.99 & .803 & $8^{\text {th }}$ \\
Sport facilities adequate & 1.91 & .699 & $9^{\text {th }}$ \\
Transport system effective & 1.88 & .742 & $10^{\text {th }}$ \\
Outdoor seating adequate & 1.65 & .694 & $11^{\text {th }}$ \\
\hline
\end{tabular}

\subsection{Assessment of Level of Usage of Outdoor Spaces}

Figure 7 below shows the level of activities within the campus outdoor spaces

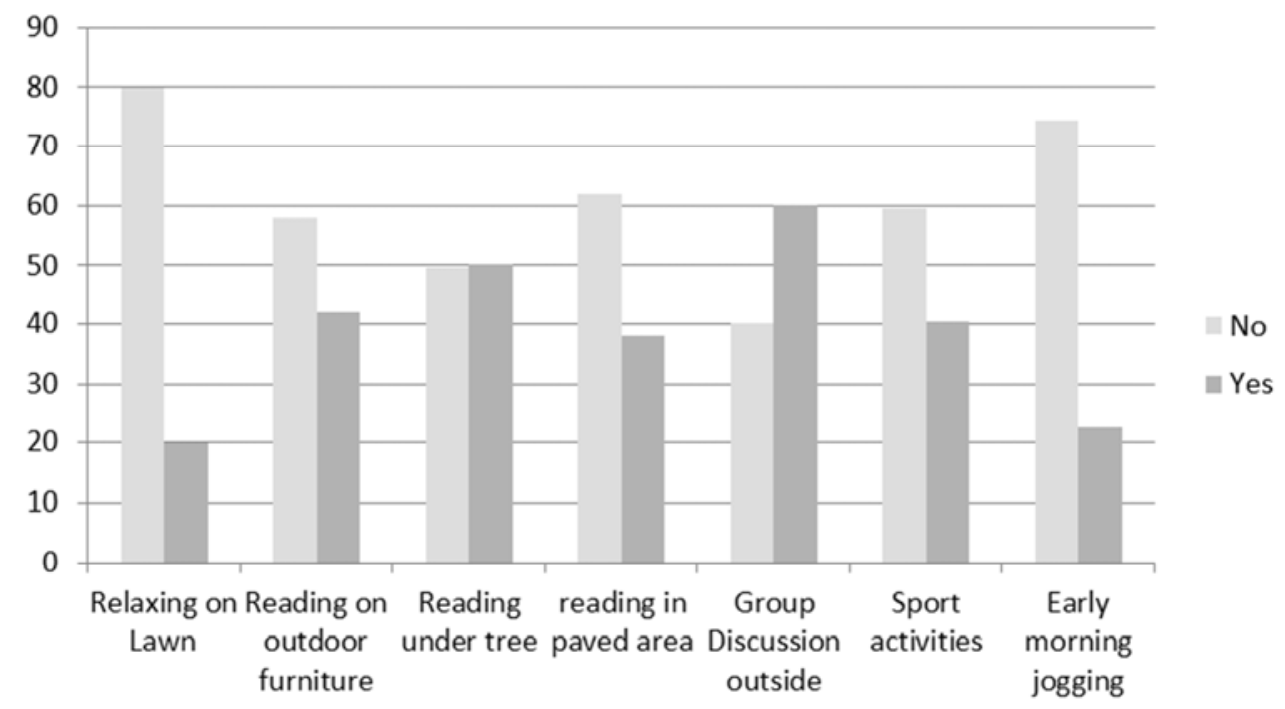

Figure 7. Frequency Distribution on Level of Usage of Outdoor Spaces.

Of the 410 respondents, $329(80.2 \%)$ of the respondents do not play/relax on the lawn while $81(19.7 \%)$ usually play or relax on green lawns. On the use of outdoor furniture, 237 $(57.8 \%)$ indicated NO while $173(42.2 \%)$ indicated YES. Students reading under the trees also differs as follows, 204
(49.8\%) do not read under the trees while 206 (50.2\%) usually study under tree shade. As regards, reading on paved open spaces, $252(61.5 \%)$ do not read on paved open spaces while $158(38.5 \%)$ do use paved open space for reading. Furthermore, $164(40.0 \%)$ do not engage in group discussion 
outside the classrooms whereas a higher percentage representing $246(60.0 \%)$ reported their frequent involvement in group discussion outside the classrooms. The respondents involvement in sporting activities differs as follows, 244 $(59.5 \%)$ are not involved in any sporting activities while 166 $(40.5 \%)$ are usually engaged in sporting activities. In a similar perspective, $305(74.4 \%)$ are not engaged in early morning jogging while only $93(22.7 \%)$ do participate in this physical activity.

\subsection{Ranking of Level of Outdoor Spaces Usage}

As indicated in Table 3, "Group discussion" in the outdoor spaces has the highest Mean Score $(M=1.60)$ suggesting that most respondent engages in group interactions within the outdoor spaces, however "Relaxing on the lawns" has the lowest Mean Score $(\mathrm{M}=1.21)$. The Standard Deviation ranges between 0.513-0.437 revealing relative consistency in the level of usage among the respondents. This analysis reveals that high level of social interaction happens in the outdoors in form of "group discussion". In addition, analysis suggests that despite the limited quantity of outdoor furniture, the level of usage by the students for learning and social activities is still relatively high. This aligns with scholars arguments that open spaces are usually areas for recreation and interactions, as such, has great influence on physical wellbeing, social connections, quality of living and academic success [19;20; 21].

Table 3. Mean Score, Standard Deviation and Ranking of outdoor spaces usage.

\begin{tabular}{llll}
\hline Variables & Mean & Std. Deviation & Ranking \\
\hline Group discussion outside & 1.60 & .490 & $1 \mathrm{st}$ \\
Reading under tree & 1.50 & .501 & 2nd \\
Reading on outdoor furniture & 1.42 & .494 & 3rd \\
Sporting activities & 1.40 & .491 & 4 th \\
Reading on paved area & 1.39 & .487 & 5 th \\
Early morning jogging & 1.29 & .513 & 6 th \\
Relaxing on lawn & 1.21 & .437 & 7 th \\
\hline
\end{tabular}

\section{Conclusion and Recommendations}

Quality of outdoor spaces, adequacy of outdoor infrastructure and level of usage are important criteria in campus sustainability. The outdoor spaces and landscape have potential of supporting relationship among students, improve quality of university community, and enhance psychological and behavioral values of students, which are important aspect of social sustainability. Further still, outdoor spaces plays a big role in environmental sustainability since presence of trees, green lawns, good circulation and effective road networks are essential consideration for sustainable neighborhood. Hence, the quality and adequacy of outdoor spaces have positive value in synergizing nature with the school's functions.

This study reveals that the Undergraduate Students of FUTA assessed the campus as well landscaped, very attractive, clean, well maintained and having good spatial layout, however, the students opined that the outdoor furniture are grossly inadequate. In addition, they opined that sporting facilities are insufficient, transportation system are not satisfactory and low quality of outdoor lighting. Interestingly, the study shows that "Group discussion" mostly occurs in the outdoor spaces with a significant number of students engaging in reading under trees or on outdoor furniture. On the contrary, majority of the respondents were not involved in physical activities.

The above findings then suggest the need for more holistic attention on the implementation of sustainable outdoor project that could support learning and social connectivity for the overall wellbeing of people and the environment. It is imperative to note that an academic community hosts a number of activities with varying purposes that requires proper integration in all ramifications to achieve a sustainable learning environment. Campus outdoors serve as one vital part of campus life, providing space for learning, recreation and outdoor activities, aesthetic appreciation, while functioning as a research platform for sustainable landscapes. Therefore, sustainable campus initiatives such as tree planting, parks and garden, street furniture, green infrastructure, sporting facilities, sustainable transport system as well as biodiversity conservations projects are essential tools for building environmentally friendly campus which culminates into citywide sustainability initiatives.

Indeed, achieving sustainable campus environment starts with appropriate campus planning. If sustainable design principles are incorporated into outdoor campus planning, multiple benefits could be realized such as, healthy living, ecologically and socially sensitive land use, efficient transport system method, and improved local and regional economy. Thus the following recommendations;

a. Universities should implement outdoor projects that would enhance sustainable campus environment and foster student learning.

b. Provision of outdoor furniture, green infrastructures, parks and gardens should be an integral part of campus planning and development as this aids education and social interaction.

c. Campus planning and construction practices should embrace the importance of physical quality, ecological quality, behavioural quality as well as visual quality.

d. Universities should continue to embrace the idea of good landscaping, effective maintenance and cleanliness to achieve sustainable campus environment.

\section{References}

[1] C. Boyoko, R. Cooper, C. Davey \& A. Wootton (2006). Addressing sustainability early in the urban design process. Management of Environmental Quality: An International Journal, 17 (6): 689-706.

[2] A. Sharifi (2015). From Garden City to Eco-urbanism: The quest for sustainable neighbourhood development. Sustainable Cities and Society, 20 (2016): 1-16. http://dx.doi.org/10.1016/j.scs.2015.09.002 
[3] G. Davis and M. Wolski (2009). E-waste and the sustainable organisation: Griffith University's approach to e-waste. Int. Journal Sustainable Higher Education, 10 (1): 21-32.

[4] M. Z. Abd-Razak, N. Utaberta, and H. Aisyah Nur (2012). A Study of Students' Perception on Sustainability of Campus Design: A Case Study of Four Research Universities Campus in Malaysia, Research Journal of Environmental and Earth Sciences, 4 (6): 646-657.

[5] A. Unlu, E. Erincik, C. Fitnat, S. Mehmet, G. Ervin and M. Ashkan (2009). Interface of Indoor and Outdoor Space in Buildings A Syntactic Comparison of Architectural Schools in Istanbul Proceedings of the 7th International Space Syntax Symposium Edited by Daniel Koch, Lars Marcus and Jesper Steen, Stockhol 132 (1).

[6] S. L. Johnson (2009). Improving the School Environment to Reduce School Violence: A Review of the Literature. Journal of School Health, 79 (10): 451-465.

[7] C. Franklin, T. Durkin, and S. P. Schuh (2003). The role of the landscape in creating a sustainable campus. Planning. Higher Education, 31 (3): 142-149.

[8] R. P. Dober (2012). Cited web resources on 'Campus Planning'. Reinhold Publishing Corporation.

[9] K. Lynch (1984). Good City Form. MIT Press, Cambridge.

[10] E. Willie (1992), Quality: Achieving Excellence. London, UK: Century Business.

[11] T. Smith, M. Nelischer, \& N. Perkins (1997). Quality of an urban community: a framework for understanding the relationship between quality and physical form. Landscape and Urban Planning, (39): 229-241.

[12] J. K, Adeyemi and V. O. Igbineweka (2000). "Sitting Space Utilization in Nigerian Universities: A case study of the University of Benin". Journal of Teaching Education, 4 (1): $12-23$.
[13] J. Walton, M. Sweeney, \& J. B. Fazio (2013). "how-to" guide to promoting sustainable campus landscapes. Association for the Advancement of Sustainability in Higher Education AASHE.

[14] J. A. Adedeji and J. A. Fadamiro (2015). Urban open space transition and management in Lagos, Nigeria. Management of Environmental Quality: An International Journal, 26 (6): 951965. doi 10.1108/meq-05-2013-0051.

[15] D. Aydin, and U. Ter (2008). Outdoor Space Quality: A Case Study of a University Campus Plaza. Archnet-IJAR, International Journal of Architectural Research, 2 (3): 189203.

[16] J. A., Adedeji, Y. O. Bello and J. A. Fadamiro (2011). Thermal Adaptation, Campus Greening and Outdoor Use in Lautech Campus, Ogbomoso, Nigeria. Journal of Architecture and Built Environment, 38 (2): 63-72.

[17] R. M. Downs and S. David (1973). Image and Environment: Cognitive Mapping and Spatial Behaviour. Ed. Roger M. Downs and David Stea. Chicago: Aldine Press.

[18] C. R. Kothari (2004). Research Methodology, Methods and Techniques, 2nd revised ed., New Age Techno Press, New Delhi.

[19] S. A. Oladipo (2001). "Maintenance of School Plant: A Vital Strategy of achieving Efficiency in the Universal Basic Education Scheme", African. Journal of Education Management, 9 (2): 185-195.

[20] M. Al-Homoud, and N. Abu-Obeid (2003). University Outdoor Spatial Layout Effect on Perception Of Students' Interaction And Group Seclusion. Journal of Architectural and Planning Research, 20 (3): 221-229.

[21] C. McNeely, and C. Falci, (2004). School Connectedness and the Transition Into and Out of Health Risk Behaviour among Adolescents: A Comparison of Social Belonging and Teacher Support. Journal of School Health, 74 (7): 284-292. 